\title{
Genetic diversity in a population of Dendrocalamus giganteus Wall. ex Munro (giant bamboo) in the Royal Botanic Gardens in Peradeniya, Sri Lanka.
}

\author{
S. M. S. D. Ramanayake*, V. N. Meemaduma and T. E. Weerawardene \\ Plant Biotechnology Project, Institute of Fundamental Studies, Hantana Road, Kandy.
}

\begin{abstract}
Random Amplified Polymorphic DNA(RAPD) was used to study the genetic diversity within a population comprising of 23 clumps of Dendrocalamus giganteus Wall. ex Munro in the Royal Botanic Gardens, Peradeniya. The species introduced as a single plant to Sri Lanka in 1856 showed a relatively low genetic diversity of $0.045 \pm 0.004$. The population was uniform phenotypically indicating that it was mainly raised by clonal propagation. Only seven clumps in this population flowered in recent years and seed set was rare. The presence of genetically identical groups of clumps with no polymorphism indicated clones that were possible survivors of plants established originally, 150 years ago.
\end{abstract}

Keywords: Bamboo, Dendrocalamus giganteus, dendrogram, genetic distance, RAPD, Royal Botanic Gardens, Sri Lanka.

\section{INTRODUCTION}

Dendrocalamus giganteus Wall.ex Munro (giant bamboo) is the largest of the bamboos, native to moist tropical forests of lower Burma and introduced to Sri Lanka in 1856 from Calcutta $^{1}$. Previous studies ${ }^{2}$ reported that from a single plant brought from the Royal Botanic Gardens in Calcutta, numerous plants were propagated vegetatively and planted in the Royal Botanic Gardens (RBG), Peradeniya and distributed to other parts of the country. The species flowered at irregular intervals and set seed rarely. The clumps that flowered did not always die as expected to happen as in some bamboos that perish after flowering ${ }^{1-3}$. Therefore, some of the massive clumps presently in the RBG may possibly be the survivors of the ones that were originally planted. At present there is a large number of clumps of giant bamboo in the RBG, Peradeniya and in the Kandy district and elsewhere, which may have been derived by clonal propagation or from seeds. Heterogeneity within species of bamboo is not well understood. Molecular techniques are reliable in detecting DNA polymorphisms: The study and documentation of genetic variability in bamboo is still in its early stages and only a few reports are available on the use of DNA polymorphisms in this group of plants. In previous studies ${ }^{4-6}$ Random Amplified Polymorphic DNA (RAPD) and nuclear Restriction Fragment Length Polymorphism (RFLP) have been used to identify unknown genotypes, assess genetic variations and study evolution in Phyllostachys. RAPD fingerprint profiles have also been used to characterize the species Bambusa tulda ${ }^{7}$. The present investigation was conducted to observe phenotypic variations and to detect the genetic diversity accrued during the relatively short period of 150 years since Dendrocalamus giganteus was introduced to Sri Lanka, using RAPD technique.

\section{METHODS AND MATERIALS}

Fresh young leaves were collected from 23 individual clumps of Dendrocalamus giganteus Wall. ex Munro (giant bamboo) in the RBG, Peradeniya and those growing along the Mahaweli river bank close to the RBG. These clumps were randomly selected from the total population in this study site. They were labelled and their positions were located in a map for future reference. Further, descriptions of morphological traits and flowering were noted in all clumps.

The leaves were surface sterilized, cut into small pieces and ground to a fine powder using liquid nitrogen. DNA 
extraction was carried out following the method of Weising and $\mathrm{Kahl}^{8}$, a simplified Doyle and Doyle ${ }^{9}$ protocol. About 1 to $1.5 \mathrm{~g}$ of leaf powder was homogenized in $8 \mathrm{~mL}$ extraction buffer $\{2 \%$ Cetyl Trimethyl Ammenium Bromide (CTAB), 1.4 M NaCl, $20 \mathrm{mM} \mathrm{Na}$ EDTA and $\beta$-mercaptoethanol was added last to a final concentration of $0.2 \%$ at $65{ }^{\circ} \mathrm{C}$ for over $30 \mathrm{~min}$. The incubated sample was mixed gently with $15 \mathrm{~mL}$ of chloroform:isoamyl alcohol (24:1). This was repeated using the top aqueous layer that separated after centrifugation. The crude DNA in the top aqueous layer was precipitated in 0.6 volumes of isopropanol and washed in a solution of $76 \%$ ethanol and $10 \mathrm{mM}$ ammonium acetate. RNA was removed by incubating the precipitate with RNAse at $37{ }^{\circ} \mathrm{C}$ and polysaccharides removed in $7.5 \mathrm{M}$ ammonium acetate. The DNA was precipitated in absolute ethanol, washed in $70 \%$ ethanol and finally suspended in TE (10 mM Tris-HCl: 1 mM EDTA). DNA was diluted to a working concentration of $15 \mathrm{ng} \mu \mathrm{L}^{-1}$.

Amplification was carried out in a $25 \mu \mathrm{L}$ reaction volume with $60 \mathrm{ng}$ DNA, 5 pM random 10-mer primer (Operon Technologies, California) $125 \mu \mathrm{M}$ each of dATP, dTTP, dGTP and dCTP (Promega Corporation, USA), 0.25 $\mu \mathrm{L}\left(5\right.$ units $\left.\mathrm{mL}^{-1}\right)$ Taq DNA polymerase in $10 \mathrm{x}$ polymerase buffer, $2.5 \mathrm{mM} \mathrm{MgCl}_{2}$ (Promega Corporation, USA) and overlaid with $25 \mu \mathrm{L}$ mineral oil. A negative control, with sterilized distilled water substituted for genomic DNA in the reaction mixture, was used in every batch of PCR reactions. Amplification was performed in a Sanyo DNA thermal cycler (MIR-D30) programmed for 45 cycles with the first cycle at $94{ }^{\circ} \mathrm{C}$ for $4 \mathrm{~min}, 36^{\circ} \mathrm{C}$ for $1 \mathrm{~min}$ and $72^{\circ} \mathrm{C}$ for $2 \mathrm{~min}$, followed by 44 cycles at $94^{\circ} \mathrm{C}$ for $1 \mathrm{~min}, 36^{\circ} \mathrm{C}$ for $1 \mathrm{~min}$ and $72^{\circ} \mathrm{C}$ for $2 \mathrm{~min}$.

Initially a total of 41 random 10-mer primers were tested with DNA extracted from 10 clumps of $D$. giganteus. Out of these, six primers (OPF09, OPF14, OPG19, OPH4, OPI05 and $0 \mathrm{PJ} 20$ ) that generated 8 to 12 bands were selected and tested repeatedly to make sure of the consistency of RAPD band patterns. DNA extracted from the 23 clumps of $D$. giganteus was used to generate RAPD bands with these six selected primers.

The amplified products were separated by electrophoresis in $1.5 \%$ agarose gels in $0.5 \times$ TBE $(45 \mathrm{Mm}$ Tris-Borate, 1 mM EDTA) buffer. The gels were stained with ethidium bromide and photographed on Polaroid 665 films under UV light.

The RAPD fragments (bands) generated were visually scored as 1 for presence or 0 for absence. The computer freeware package RAPDistance version 1.04 was used to analyze these data ${ }^{10}$. The monomorphic bands (all 1's or all 0's) were deleted before the genetic distances were computed, as these do not contribute to the genetic
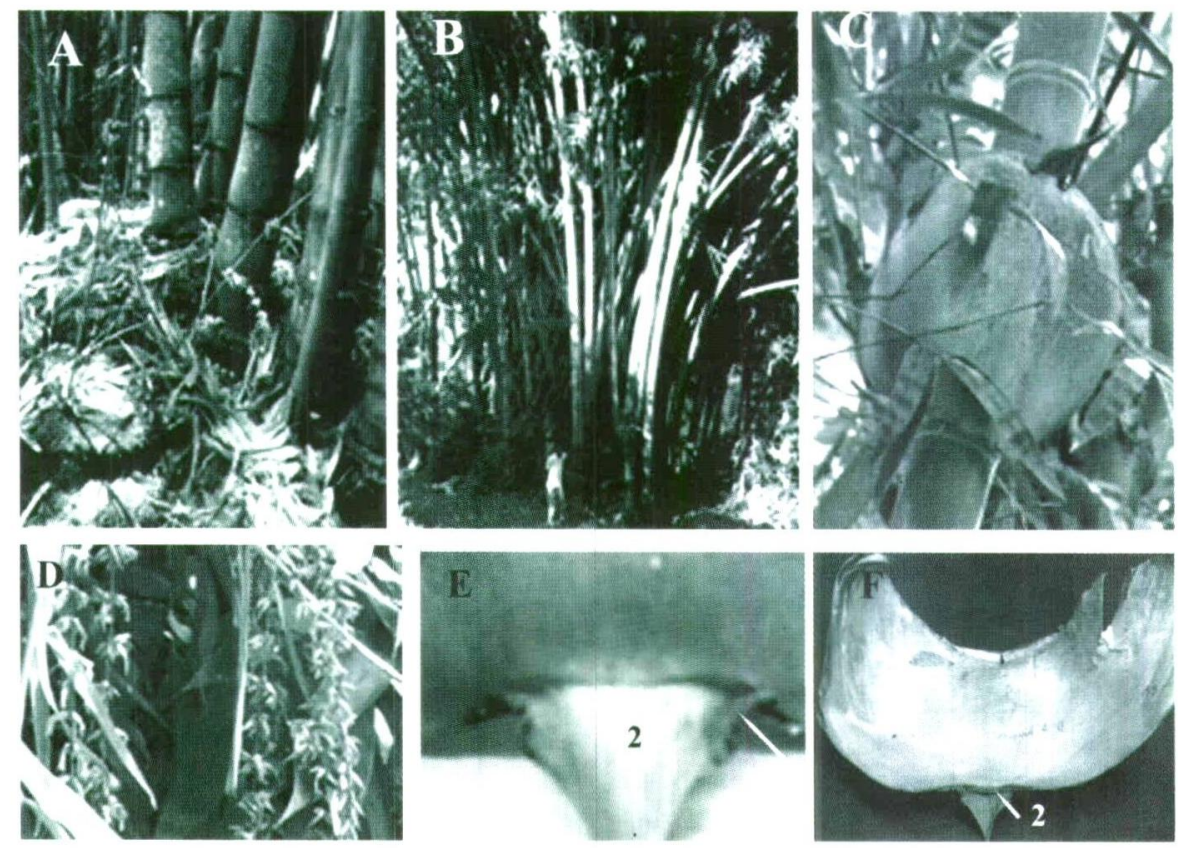

Figure 2: Morphology of D. giganteus. A-Base of a flowering clump with inflorescences emmerging from culm bases. B-A well-grown clump of D. giganteus in the RBG. C-A culm bearing a deciduous culm sheath. D-Inflorescences. E-Adaxial surface of a culm sheath showing auricles (1) and leaf blade (2). F-Abaxial surface showing ligule (2). 
relatedness of samples. From this genetic distances matrix, a neighbor-joining tree was computed. A Permutation Tail Probability (PTP) test was performed to ensure that the tree generated was not an artifact.

\section{RESULTS AND DISCUSSION}

D. giganteus is the largest of the bamboos (Figure 1: A, B and C). An average primary culm measured $19.5 \mathrm{~m}$ in height and weighed $46 \mathrm{~kg}$ after removal of secondary branches. The population of 23 clumps in this study showed that $77 \%$ of the clumps were massive with more than 200 culms. In the others, the culm number ranged from 38 to 200 , (except for clump 17, which was small and may have originated from a seed). This is an indication of the high biomass yield of a mature clump. However, the clumps have not been harvested in the population under study. Therefore all clumps had many dead or dying culms. Of the 23 clumps included in this study, 7 were flowering at the time of observation or had flowered in the last few years (Figure 1: A \& D). A few seeds were collected from two clumps but others did not set seed. Seed set is rare ${ }^{3}$. McClure ${ }^{11}$ who studied bamboos under cultivation concluded that introduced species sometimes flower with little or no seed set. Our observations showed that in D. giganteus, the lemma and palea of florets do not open. The anthers, which are large, are able to emerge by pushing them apart during anthesis but the stigma, which

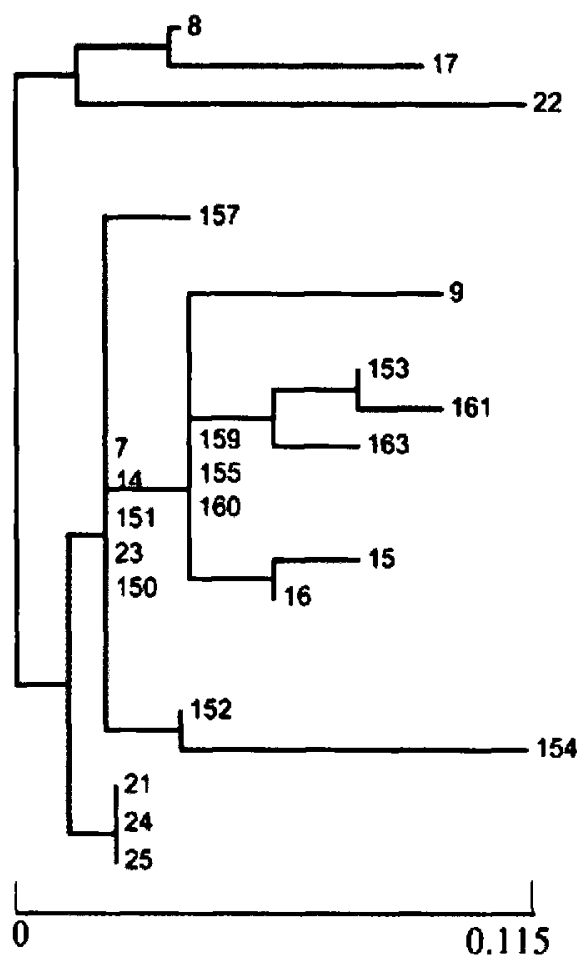

Figure 1: Dendrogram of the $D$. giganteus population in the Royal Botanic Gardens, Peradeniya, (individual clumps are designated by numbers) is relatively thin, did not emerge in this manner, except rarely, to enable pollination and seed set.

The vegetative characters observed are in accordance with the description of this species by Senaratne ${ }^{12}$. The culms are bluish green with a powdery bloom when young. Nodes smooth but more ridged at culm base (Figure 1:A and $C$ ). Mean culm girth in the population was 58.40 $\pm 1.96 \mathrm{~cm}$. ' $B$. tulda populations in India are reported to show culm variations such as yellow striations and swollen internodes? ${ }^{7}$. In vegetative morphology this species closely resembled $B$. nutans, $B$. auriculata and $B$. arundinacea.' In $B$. vulgaris too, culm colour varies from green to yellow and some have yellow and green striations. There were no variations in culm colour or shape in D. giganteus and it could be morphologically distinguished from the relatively few species of bamboo in Sri Lanka. The culm sheath, which is a specific character used in species identification did not show a variation among individual clumps (Figure 1: C, E\& F).

Culm sheath, deciduous at time of secondary branch development, is broad and coriaceous. The adaxial surface is pubescent with dark brown hairs and the abaxial surface is glossy. The auricles are wavy, ear-shaped and equal in size (Figure 1: E). The culm leaf blade is obovate with a pointed tip (Figure 1: E 2) and ligule is prominent (Figure 1: F). The leaf blade of sheaths along the culm elongates gradually to the top of culm.

The RAPD fragments varied according to the combination of primer and DNA sample. Of a total of 41 primers tested, 4 did not give amplifications. The other primers generated a range of 2 to 12 bands. The six selected Operon primers (OPF 09, OPF 14, OPG 19, OPH 04, OPI 04 and OPJ 20), each of which generated 8 to 12 bands, gave a total of 36 bands. Of these, 24 bands that were polymorphic were used to study the genetic distance and generate a neighbour-joining tree.

The distance matrix of the $D$. giganteus population (Figure 2) showed that the distance among clumps was low ranging from 0 to 0.115 with a mean of $0.045 \pm 0.004$. The highest mean genetic distance of $0.079 \pm 0.004$ was shown by the individual numbered 22 , which was a massive clump. It had the highest distance of 0.115 from clump number 154 , which was also massive with a few culms bearing inflorescences at the time of study. The clumps $7,14,23,150$ and 151 were genetically similar and had the lowest mean distance of $0.018 \pm 0.004$ from all other clumps. Of these, clump 23 is used to typify the species in the RBG, with a description given alongside. It was circular with the center bare of older culms indicating that it was very old. The other clumps genetically similar to 
this were also massive clumps and all of them could be survivors of those originally planted in the RBG. The clumps 150,151 were spatially very close and may have been a single clump that separated during growth over a long period. Clumps 21, 24 and 25 were also genetically similar with 24 and 25 lying close together and possibly divided from a single clump that existed earlier. In a wider study that included seed raised offspring in D. giganteus, a higher mean genetic distance was detected, mainly contributed by seed raised offspring (unpublished data). Previous studies ${ }^{4}$ used RAPDs to study the genetic diversity in Phyllostachys and found that although there was high diversity between species, it was not so within forms or varieties, which could however be phenotypically identified by culm colour etc. Scientists ${ }^{7}$ also observed phenotypic variations in $B$. tulda populations but they did not detect DNA polymorphisms between or within zopulations using RAPD technique. Friar and Kochert ${ }^{5}$ who used a number of low copy number probes detected unique RFLP patterns that were species specific in Phyllostachys. Different accessions of the same species, which morphological differed, also had identical RFLP patterns. They suggest that the use of more probes and enzyme combinations may generate RFLP patterns that enable distinguishing between these accessions. Thus, DNA techniques are a valuable tool in the study of bamboo systematics and population biology.

\section{CONCLUSION}

The low genetic diversity and the phenotypic uniformity in the small giant bamboo population in the RBG indicate that, the population may have been mainly derived vegetatively, during the short period of 150 years since its introduction to Sri Lanka. The massive size of the clumps indicated that some of them are very old and the genetic similarity between some of these clumps indicate that they may be ones planted originally in the RBG, 150 years ago. Thus, no major changes seemed to have occurred genotypically in this small population within the RBG. Selection of clumps having favorable traits for large-scale propagation would not be necessary. However, introduction of variability from its native habitat and wide crossing may result in improving the species.

\section{Acknowledgement}

We are grateful to Mr Everard Jayamanne of the Coconut Research Institute for his advice in improving RAPD techniques. The Royal Botanic Gardens, Peradeniya is acknowledged for providing bamboo plant material.

\section{References}

1. Mc Millan H.F. (1908). Flowering of Dendrocalamus giganteus, the 'giant bamboo'. Annals of the Royal Botanic Gardens, Peradeniya 4:12.3-129.

2. Petch T. (1925). Gregarious flowering. Annals of the Royal Botanic Gardens, Peradeniya 9: 101-116.

3. Ramanayake S.M.S.D. \& Yakandawala Y. (1998). Incidence of flowering, death and phenology in the giant bamboo (Dendrocalamus giganteus Walt. ex Munro). Annals of Botany 82: $779-785$.

4. Geilis J., Everaert I. \& De Loose M. (1997). Genetic variability and relationships in Phyllostachys using random amplified polymorphic DNA. In: The Bamboos. Linnaean Society Symposium Series No. 19. (Ed. G.P. Chapman). Academic Press, London. pp $107-124$.

5. Friar E. \& Kochert G. (1991). Bamboo germplasm screening with restriction fragment length polymorphisms. Theoretical and Applied Genetics 82: 697 - 703.

6. Friar E. \& Kochert G. (1994). A study of genetic variation and evolution of Phyllostachys (Bambusoideae:Poaccac) using nuclear restriction length polymorphisms. Theoretical and Applied Genetics 89: 265 - 270.

7. Bhattacharya S., Das M., Bar R. \& Pal A. (20)(16). Morpholugical and molecular characterization of Bambusa tulda with a note on flowering. Annals of Botany 98: $529-535$.

8. Weising K. \& Kahl G. (1997). Hybridization-based microsatellite fingerprinting of plants and fungi. In: DNA markers; protocols, applications and overviews (Eds. G. CalctanoAnolls \& P.M. Gresshaff ). pp. 27-53.

9. Doyle J.J. \& Doyle J.L. (1990). Isolation of plant DNA from fresh tissues. Focus 12: $13-15$.

10. Armstrong J., Gibbs A.J., Peakall R. \& Weiller G. (1994). "The RAPDistance Package". Http//life.anu.edu.au/pub/ software/RAPDistance or http/life.anu.edu.au/molecular/ software/rapd.html. Accessed 20/02/200)6.

11. McClure F. A. (1966). The Bamboos, a Fresh Perspective, pp. 347. Harvard University Press, Cambridge.

12. Senaratne S.D.J.E. (1956). The Grasses of Ceylon. pp. 22 -30. The Government Printer, Colombo. 